\title{
Ambiances
}

anbiances Environnement sensible, architecture et espace urbain Varia | 2015

\section{Aesthetic Sensibility}

Sensibilité esthétique

\section{Arnold Berleant}

\section{OpenEdition}

\section{Journals}

\section{Electronic version}

URL: http://journals.openedition.org/ambiances/526

DOI: 10.4000/ambiances.526

ISSN: 2266-839X

\section{Publisher:}

Direction Générale des Patrimoines - DAPA - MCC, UMR 1563 - Ambiances Architectures Urbanités (AAU)

\section{Electronic reference}

Arnold Berleant, «Aesthetic Sensibility », Ambiances [Online], Varia, Online since 30 March 2015 connection on 10 December 2020. URL : http://journals.openedition.org/ambiances/526 ; DOI : https://doi.org/10.4000/ambiances.526

This text was automatically generated on 10 December 2020.

\section{(c) (i) $९$}

Ambiances is licensed under a Creative Commons Attribution-NonCommercial-NoDerivatives 4.0 International License. 


\title{
Aesthetic Sensibility
}

\author{
Sensibilité esthétique
}

Arnold Berleant

\section{Introduction}

1 It is common to think of aesthetics as a theory that accounts for the beauty or the pleasing quality of things. This is not far from the mark. When philosophers speak of aesthetics as a scholarly discipline, they usually associate it with the philosophy of art and the special value that the arts and nature possess. Over the past several decades, however, the arts and aesthetic practices have continued the direction of the past century in expanding their domain still more rapidly. The application of aesthetic values to environment is one instance of this expansion, and environmental aesthetics has emerged as an important part of the enlarged scope of aesthetics ${ }^{1}$. More recently, aesthetics has been applied to still other domains of experience, such as the aesthetics of everyday life, the aesthetics of food, the aesthetics of community, political aesthetics, and still others (Light \& Smith, 2005; Saito, 2007; Mandoki, 2007; Leddy, 2012; Sartwell, 2010; Berleant, 2010). The understanding of environment itself has grown to include not only the scenic landscape but the urban landscape and the industrial landscape, including their negative aspects. Moreover, the growing awareness of other cultures and their traditions of aesthetic satisfaction have forced our thinking to expand into still other dimensions.

2 Expanding the scope of aesthetics raises challenging questions about the experience of appreciation. Traditional accounts of aesthetic appreciation are inadequate to identify and illuminate the perceptual satisfactions that these new applications evoke. But not only does an enlarged range of aesthetic appreciation recognize beauties beyond the arts. It also must account for the range of aesthetic perception into the oneiric, the bizarre, and the terrible, while the social and political significance of aesthetic values has led to the recognition of a wide range of such values, not all of them positive. 
These challenges to aesthetic understanding have made the task of scholars both more important and more difficult. For their concerns now include not only art and the beauty of nature but the full range of life experience, as well, and this has given aesthetics increased significance and has produced greater confusion. What do these domains of experience have in common? Is there something that all these modes of experience share in considering them aesthetic? This is the challenging question for aesthetics in our time.

\section{The domains of aesthetics}

4 The key to understanding the aesthetic lies, I believe, in the etymology of that word. The term "aesthetics" is a transliteration of the Greek aisthessis, which means perception by the senses. Alexander Baumgarten kept close to the original Greek meaning when, in the mid-eighteenth century, he first defined aesthetics as "the science of sensory knowledge directed toward beauty" and regarded art as "the perfection of sensory awareness" (Baumgarten, 1750). While the meaning of aesthetics has since then become both vaguely generalized to signify something whose appearance is attractive and pleasing, its original philosophical meaning led to aesthetics becoming a technical discipline of philosophy with its imponderables of definition and ontology.

5 First, however, let us consider more deliberately the various domains of aesthetics. As a philosophical discipline, aesthetics has centered around understanding beauty in art and in nature. Whether aesthetics focuses on the one or the other varies with the time and place. Of course, people appreciated artistically fashioned objects since the beginnings of human civilization. The earliest surviving artifacts show evidence of workmanship and decoration that indicates deliberate care in fashioning utilitarian objects beyond functional necessity (Shiner, 2001). Then there are the seemingly gratuitous petroglyphs and images that were inscribed prehistorically on stone outcroppings and the walls of caves in many locations, and ornamental objects and jewelry are typically found in prehistoric grave sites. These indicate clearly that an aesthetic sensibility has been present from the beginnings of human social organization, if not among our pre-human ancestors ${ }^{2}$.

6 In the history of Western civilization, speculation and theories about the arts occurred early, too, beginning with the golden age of Greek civilization some twenty-five hundred years ago. But it was not until the middle of the eighteenth century that modern aesthetic theory began with Baumgarten's treatise and, at the end of that century, received its most influential formulation with Kant's Critique of Judgment (Kant, 1790). After two centuries of commentary, Kant's views continue to dominate aesthetic query. Let us recall in brief the main tenets of that understanding. It affirms that our aesthetic judgment of an object is inevitably subjective and cannot even be subsumed under a concept because we cannot affirm the existence of the object, which would imply some access to objectivity and universality. Thus aesthetic judgment is non-cognitive. The problem then is to establish some connection between our subjective judgments of taste and the object. Kant attempted this by removing any desire or other interest and emulating the disinterestedness that has made scientific knowledge possible in the effort to achieve the semblance of universality by means of a common sense (sensus communis) (Ibid., §2, §8, \$22). This is a specious argument for universality and just as contrived as Descartes' similar attempt to bridge the distance between subject and object by means of the pineal gland. 
7 Movement and change in aesthetic appreciation have occurred, nevertheless, in practice if not in theory. The eighteenth and nineteenth centuries gave increasing attention to natural beauty. And while the twentieth century tended to refocus on works of art, recent decades have witnessed not only renewed appreciation of nature but the enlargement of that interest. Environment is now understood more broadly to include the city and the built landscape more generally, as well as wild nature. What is more, aestheticians have extended their scope to embrace the world of everyday experience. In these domains, disinterested contemplation is unlikely and different ways of explaining aesthetic pleasure have been proposed ${ }^{3}$.

These developments in art and aesthetic appreciation have strained the theoretical unity of traditional aesthetics, which cannot easily accommodate these changes. With over a century of innovation in the arts and the vast enlargement and complexity of appreciative experience, the customary rubrics of explanation have become increasingly inadequate and even irrelevant. Indeed, developments over the past century have challenged the very conceptual frame of aesthetics: the meaning of art, the condition and character of appreciation, and the scope and place of aesthetic values. Art and appreciation have been re-cast, and aesthetic theory must be renewed to accommodate them. There is a need to return to the etymological meaning of the term "aesthetics" and Baumgarten's emphasis on perception by the senses. Let us consider how this may go.

\section{From objects to experience}

9 It is not surprising that philosophical understanding underlies both traditional aesthetics and its alternatives. Coincident with the emergence of modern aesthetics at the end of the eighteenth century was the establishment of the modern scientific world view. Formulated by Descartes and implemented by Newton and the pantheon of scientific explorers who followed, the natural world was laid open first to mathematical and then to empirical investigation. What facilitated this was the ability to study nature impersonally and objectively. The objectification of nature became the key, and philosophical aesthetics carried out the Cartesian revolution by objectifying the objects of appreciation. Art came to mean objects, works of art. Nature, too, was turned into scenery viewed at a distance, favored by the popular Claude glass that turned landscapes into reflected, composed images on a mirror.

From the hindsight of the present, the succession of disruptive movements that occupied the world of art from the late nineteenth century to the present day can be regarded as a rejection of the convention in thinking of art as an object, a distinctive object. The gradual and increasing emancipation from close representation led, in modern painting, to ways of giving pictorial form to the perception of light, of movement, of mass, and of form, transforming them from abstractions into perceptual experience. In the visual arts, impressionism, cubism, futurism, and dada began a direction that turned the art object into an occasion for perceptual, sensible engagement. As in the transition in music from polyphony to tertiary harmony, art has again led theory.

11 This changes our understanding of aesthetics into a descriptive and not necessarily celebratory study of perceptual experience. It must now accommodate a complete range of negative as well as positive values. Nor is aesthetic theory confined to the fine arts and nature only: an aesthetic dimension pervades the human world. What emerges is the 
understanding that aesthetic appreciation is not an object-centered response that requires a psychological remove and a disinterested attitude. Rather, it is a complex multi-sensory perceptual engagement by means of a cultivated sensibility.

This broad vision of sensible experience must be expanded still further. It must be seen as a field experience ${ }^{4}$. Sensible experience is part of an existential context that includes the geological strata that underlie all activity, the modifications of the earth's surface and the structures that result from human activities in fashioning the immediate conditions of living, the behaviors that promote sustenance and wellbeing, and the social relations and patterns that constitute the cultural activities of human living under the particular conditions of time and place. The human organism is infused by the materials and forms of nourishment that are obtained and shaped through the techniques of food production and preparation that are available in the social and cultural setting in which people live, guided by the customs, language, concepts, belief structures, and particular meanings that are prevalent, and finally by the forms of sensibility that are customary. Living, then, is a perceptually selective, discriminating process in which everyone receives and contributes. It is a condition of continuities within which we make distinctions, separations, and divisions based on need, customary practices, and tradition. The perceptual factors of this field reflect the full range of sensation and sensible awareness as it is filtered and discriminated in participatory activities. We inhabit, then, a field of sensate activity that rests on sensation but as sensible perception infused by and related to all the conditions that affect and qualify human experience. Let me try to identify and explore aesthetic sensibility.

\section{Sensibility}

13 The historical and theoretical development I have outlined culminates in the insight that aesthetics is, at its base, a theory of sensibility. This illuminates the arts of the past as well as of our time, and it recognizes aesthetic value as an often hidden feature of all experience. Such a generalized aesthetic enables us to recognize the presence of a pervasive aesthetic aspect in every experience, whether uplifting or demeaning, exalting or brutal ${ }^{5}$. It makes the constant expansion of the range of art and of aesthetic experience both plausible and comprehensible. How, then, can we understand sensibility?

By sensibility I mean perceptual awareness that is developed, guided, and focused. It is more than simple sensation, more than sense perception. Perhaps one can consider it educated sensation. It requires the perceptual knowledge and skills that we are continually enhancing in and through our encounters and activities. Aesthetic sensibility develops and uses this capacity at the deliberate center of conscious experience. In Western cultures, the arts have been the primary medium for promoting such awareness, and we can consider changes in artistic style, the emergence of new movements, and even entire historical periods in the arts as fundamentally changes in sensibility. Looking at culture change more broadly, we can regard fashion, etiquette, and behavior patterns in general as part of the prevailing sensibility of a place and time. So while sensibility is not a term common in the literature of aesthetics, what it denotes is not new or unfamiliar. Indeed, one could write a history of aesthetics around this idea, ranging from contexts in which sensible experience was impeded, repressed, or hidden behind conventions of acceptability, to arts and artists whose work developed out of its limitless possibilities. 
Human activities seem always to have exhibited qualitative interests in fashioning craft objects, as well as decorative and ornamental ones, together with those we now call artistic. All of these display an attention and delight in features and qualities we now call aesthetic, such as the tactile appeal of surfaces; the attraction of pattern, regularity, and coloration. These characteristics often join with signs of care, precision, and formal coherence that are sometimes related to practical or functional requirements but often stand quite apart from them. And, of course, there are those features of objects that are superfluous for practical purposes but are nevertheless valued and deliberately included. In addition to craft objects there are ceremonial and ritual activities and the narrative skills of bards, all of which display a sensitivity in their production beyond simply accomplishing a given task. The senses are multiply involved and are distributed nonexclusively throughout all these activities. For no art activity relies on a single sense while, at the same time, sensory experience is suffused with meaning and associations, often implicit or hidden. A developed sensibility responds to all of these.

The multiple facets of life experience become strata that the fine arts often draw on and extend. From the start, sense experience was not isolated or channeled, and later appropriations of sensation as "subjective", mechanical, or purely physiological are aberrations rather than purifications. Sensibility, informed by sensory experience, is therefore not purely "subjective," mental, or exclusively private but a characteristic of awareness by living humans in a context that is seamlessly natural, social, structural, and cultural.

17 A heightened sensibility, however, while essential, does not in itself fully describe the finely-honed perceptual engagement that strives to fulfill the possibilities of aesthetic appreciation. Human sensibility enters into every region of experience and a distinctively aesthetic mode is widely recognized. A theory of aesthetic sensibility, however, needs to recognize and discriminate its nuances. We can begin by identifying some of the most important contributing dimensions.

1. Perceptual acuteness. Sensibility involves sensory awareness that exhibits sharp, focused attention to all perceptual aspects of an aesthetic situation. This is the primary condition of aesthetic appreciation.

2. Perceptual discrimination. This recognizes the multi-sensory and synaesthetic nuances in sensible experience, such as its subtle, shifting palette of tonalities, its multiple layers, and its textural qualities.

3. Focus. Aesthetic sensibility is not simply general perceptual sensitivity; it is centered. Attention may be on a particular object or it may be on a region of varying breadth. In addition, the sensible aspect of the focus may vary by emphasizing different sensory combinations and degrees of intensity.

4. Intensity. Perception may range in intensity from the barely conscious to fully acute awareness. The degree of intensity may be the closest correlate to its vividness and force.

5. Emotional sensitivity. The somatic reception and response to perceptual stimuli are an essential part of aesthetic sensibility. Reception that is mistakenly understood as subjective or mentalistic does not recognize the essential, constitutive, affective contribution that the perceiver makes to the aesthetic situation as an embodied being who is at the same time conditioned by physical, historical, and cultural influences.

6. Atmosphere ${ }^{6}$. Every perceptual situation has a general quality that may elude clear identification. It is an ineffable but nonetheless distinctive tone or character of the field of experience: magical, tiresome, depressing, enhanced, exalted. Such words are only approximate and inadequate identifiers of what poets are best at evoking. Atmosphere is not 
apprehended by direct sensory perception but is rather apprehended as a general bodily awareness capable of degrees of intensity.

7. Perceptual engagement. The cornerstone of the perceiver's contribution lies in the liveliness of appreciative perception. Appreciation activates the perceptual possibilities of the situation. It is a unique contribution that each person makes through the distinctive capacities (physical, cognitive, and mnemonic) the perceiver activates in the occasion.

8. Perceptual meaning. Meaning comes last so as not to overshadow or blind the perceptual force that is the substance of aesthetic appreciation. Appreciation is not a cognitive act but often involves embodied meaning. Meanings that are bound up in perception, meanings that are experienced, do not replace perception but may reinforce and enhance it.

\section{Aesthetics and sensibility} object occupies the center of perceptual attention. It may take the form of an art object, such as a painting, sculpture, musical composition, literary work, or any other object of artistic fashioning. As an art object it is the product of some activity; it is something made. As an aesthetic object, it is the object as it works in perception. Here sensibility consists in a complex focused attention on every perceptual feature or aspect of the object, at how it interacts with other factors in the aesthetic (perceptual) field, and at its varying strength and stability. Considering the art object as an aesthetic object emphasizes its sensory qualities in their complexity and interrelationships. Sensible appreciation lies in apprehending how the object exhibits and works through its perceptual qualities. It is a process of engaging perceptually with the object, not regarding it distantly and dispassionately. Any judgment that is arrived at rests on this perceptual foundation, enhanced by knowledge and past experience. Such perceptual openness enables us to recognize experientially how well the object functions in that situation and, if desirable, to form a judgment about its success. Such a judgment is the product of a complex perceptual process and can provide a clear grounding for assessing the object's success. We have, then, the possibility of positive and negative aesthetic judgment along a multi-dimensional scale, for no object is an undifferentiated whole. Perceptual success, then, is the criterion for a positive and negative aesthetics, the negativity being based on perceptual failure.

Aesthetic sensibility, then, can clarify the various arts and art objects, each through its distinctive perceptual capacities. Art today has moved to abandon the fixation on objectcentered experience in such developments as performance art, community art, improvisational dance, improvisation theater, and reality art. In dialogical or relational art, the artist may invite the audience into a process that shares the responsibility and authorship of the work. This turns the work into more of a process, performance activity, or duration than a fixed object. It can illuminate nature whether perceived as landscapes, scenes, or discrete objects. Similarly, aesthetic sensibility has particularly rich possibilities for enhancing our perception of the built environment through multisensory bodily engagement. Such aesthetic engagement transforms our environmental perception of space, mass, and density when apprehended not as abstractions but in the lived acute sensory experience of everyday life. It is important to include in the domain of sensibility what may be called virtual sensibility, perception in literature and imaginative perception, more generally. 


\section{Conclusion}

No experience is value-free, for everything we encounter and undergo is colored by our interests, responses, and attention. Thus the search for the satisfaction of sensible experience comes from a thirst for positive perceptual value, which we find can be fulfilled by the perceptual satisfactions of the arts, natural beauty, and the immensely rich perceptual forms and details of the world of human life. This account of a perceptually-based aesthetics returns the meaning of aesthetics to its origins and reaffirms the critical place of sensation and sense perception. And this is but the start, since sense perception is never simple sensation or pure perception but a complex, multifaceted field experience. When such experience centers around the occasions of art and beauty, sensation is focused, dwelt on, cultivated. This is what is meant by sensibility, and it leads to considering aesthetics as the theory of sensibility.

\section{BIBLIOGRAPHY}

Baumgarten, Alexander Gottlieb. 1750. Aesthetica. Vol. I. Frankfurt a. O.

Benjamin, Walter. 1969. The Work of Art in the Age of Mechanical Reproduction. In: Illuminations (edited and introduced by Arendt, Hannah). New York: Schocken Books. p. 217-252.

Berleant, Arnold. 2001 [1970]. The Aesthetic Field: A Phenomenology of Aesthetic Experience.

Cybereditions, http://www.cybereditions.com/webc/runisa.dll?

sv:CYVIEWSUMMARY:1812269799:10009.

Berleant, Arnold. 1992. The Aesthetics of Environment. Philadelphia: Temple University Press.

Berleant, Arnold. 2005. Aesthetics and Environment, Variations on a Theme. Farnham, UK \&

Burlington, VT: Ashgate, 2005.

Berleant, Arnold. 2010. Sensibility and Sense: The Aesthetic Transformation of the Human World.

Exeter, UK: Imprint Academic.

Berleant, Arnold. 2012. Aesthetics beyond the Arts. Farnham, Surry: Ashgate.

Böhme, Gernot. 2013. The art of the stage set as a paradigm for an aesthetics of atmospheres.

Ambiances [online], Rediscovering. Available online at: http://ambiances.revues.org/315 (consulted on December 05, 2014).

Brady, Emily. 2003. Aesthetics of the Natural Environment. Edinburgh: Edinburgh University Press.

Carlson, Allen. 2000. Aesthetics and the Environment. New York: Routledge.

Carlson, Allen. 2009. Nature and Landscape: An Introduction to Environmental Aesthetics. New York: Columbia University Press.

Carlson, Allen \& Berleant, Arnold (eds.). 2004. The Aesthetics of Natural Environments. Peterborough, Ont.: Broadview. 
Kant, Immanuel. 1790. Critique of Judgment.

Kemal, Salim \& Gaskell, Ivan (eds.). 1993. Landscape, Natural Beauty, and the Arts. Cambridge and New-York: Cambridge University Press.

Leddy, Thomas. 2012. The Extraordinary in the Ordinary: The Aesthetics of Everyday Life. Peterborough, Ont.: Broadview.

Light, Andrew \& Smith, Jonathan M. (eds.). 2005. The Aesthetics of Everyday Life. New York: Columbia University Press.

Mandoki, Katya. 2007. Everyday Aesthetics: Prosaics, the Play of Culture and Social Identities. Aldershot and Burlington: Ashgate.

Moore, Ronald. 2008. Natural Beauty: A Theory of Aesthetics beyond the Arts. Peterborough, Ont.: Broadview.

Naukkarinen, Ossi. 2007. Art of the Environment. Helsinki: Okka.

Saito, Yuriko. 2007. Everyday Aesthetics. Oxford: Oxford University Press.

Sartwell, Crispin. 2010. Political Aesthetics. Ithaca and London: Cornell University Press.

Sasaki, Ken-ichi. 2012. The Faculty of Feeling. Diogenes. vol 59, n 1-2, p. 21-31.

Seamon, David (ed.). 1993. Dwelling, Seeing, and Designing: Toward a Phenomenological Ecology. Albany, N.Y.: SUNY Press.

Sepänmaa, Yrjö. 1993. The Beauty of Environment: A General Model for Environmental Aesthetics. Denton, Tex.: Environmental Ethics Books.

Shiner, Larry. 2001. The Invention of Art. Chicago: University of Chicago Press.

\section{NOTES}

1. A large literature has grown in environmental aesthetics. See Berleant, 1992; 2005; 2012. Other important work includes: Brady, 2003; Carlson, 2000; 2009; Moore, 2008; Naukkarinen, 2007; Seamon, 1993; Sepänmaa, 1993; Kemal \& Gaskell, 1993. An extensive bibliography up to its date of publication can be found in Carlson \& Berleant, 2004.

2. Animal behavior in courting often exhibits what we consider aesthetic attributes similar to those we recognize in dance, architecture, and design. The behavior of male birds is a common example, as in the Australian bower bird and the peacock.

3. This has been a principal preoccupation of my own work in which I have proposed the unity of perceiver and object in an aesthetic field, and have developed aesthetic engagement as characterizing appreciative experience. The present essay carries this effort still further by developing aesthetic sensibility as the central factor in appreciation.

4. The concept of an aesthetic field describes the complex context of which appreciative experience is a part. See Berleant, 1970, 2001.

5. I have developed the idea of the normative range of aesthetic value in Berleant, 2010. In writing of sensibility, Ken-ichi Sasaki notes that the Japanese word "kansei" literally means the faculty of feeling (Sasaki, 2012).

6. See Böhme, 2013; see also Benjamin's use of “aura" (Benjamin, 1969). 


\section{ABSTRACTS}

Aesthetics is fundamentally a theory of sensible experience. Its scope has expanded greatly from centering on the arts and scenic nature to the full range of appreciative experience. Expanding the range of aesthetics raises challenging questions about the experience of appreciation. Traditional accounts are inadequate to identify and illuminate the perceptual experiences that these new applications evoke. Considering the range of environmental and everyday occasions aesthetically changes aesthetics into a descriptive and not necessarily celebratory study of sensible experience, for it must now accommodate a complete range of negative as well as positive values.

L'esthétique est fondamentalement une théorie de l'expérience sensible. Son champ s'est largement développé, depuis le centrage initial sur les arts et les paysages pittoresques, jusqu'à la prise en compte de l'ensemble des expériences appréciatives. Ce développement du champ de l'esthétique soulève des questions fondamentales sur l'expérience de l'appréciation. Les cadres traditionnels ne sont pas adéquats pour identifier et clarifier les expériences perceptives portées par ces nouveaux questionnements. Prendre au sérieux la dimension esthétique de notre environnement quotidien transforme l'esthétique en une approche descriptive, et plus nécessairement laudative, de l'expérience sensible, en ce qu'elle doit désormais tenir compte de toute une gamme de valeurs négatives autant que positives.

\section{INDEX}

Mots-clés: esthétique, sensation, perception sensorielle, sensibilité

Keywords: aesthetics, sensation, sense perception, sensibility

\section{AUTHOR}

\section{ARNOLD BERLEANT}

Arnold Berleant is Professor of Philosophy (Emeritus) at Long Island University (USA). His work ranges over aesthetics, the arts, ethics, and social philosophy, and he has lectured and written widely in these areas, both nationally and internationally. Berleant is the author of numerous articles as well as eight books on aesthetics, the arts, and especially the aesthetics of environment. He is also the founding editor of the on-line journal, Contemporary Aesthetics. ab@contempaesthetics.org 